Technical Note

\title{
Using a Helicopter to Measure River Discharge under Extreme Environmental Conditions: A Methodological Approach on the Sagavanirktok River, Alaska
}

\author{
John Keech ${ }^{1}$, Mike Terwilliger ${ }^{2}$, Joel Bailey ${ }^{1}$ and Horacio Toniolo ${ }^{1, *}$ \\ 1 Water and Environmental Research Center, University of Alaska Fairbanks, Fairbanks, AK 99775, USA; \\ johnalbertkeech@gmail.com (J.K.); jpbailey@alaska.edu (J.B.) \\ 2 Quicksilver Air Inc., Fairbanks, AK 99707, USA; mike.j.terwilliger@gmail.com \\ * Correspondence: hatoniolo@alaska.edu; Tel.: +1-907-474-7977
}

Received: 23 April 2018; Accepted: 25 May 2018; Published: 28 May 2018

\begin{abstract}
River discharge is a critical variable in many aspects of hydrology, particularly river mechanics. Due to the importance of river discharge, the standards for performing measurements are already established. In the extreme environmental conditions of breakup in Arctic regions, field crews face significant challenges in carrying out measurements, including risks to personnel, equipment safety, and river access difficulties. The use of a helicopter in performing river discharge measurements with these challenges provides an alternative to using a boat. We present the details of measuring river discharge with the help of a helicopter along the braided Sagavanirktok River on the Alaska North Slope.
\end{abstract}

Keywords: discharge measurements; spring breakup; arctic environments

\section{Introduction}

River discharge represents one of the outputs of a watershed. In some cases, where evapotranspiration and percolation are limited or can be considered negligible, as in arctic regions, discharge is the most important output variable to the hydrology of the watershed. Due to the significance of river discharge, standards for carrying out the measurements are already established by agencies collecting these data, for instance, the U.S. Geological Service (USGS) [1].

The task of collecting river discharge during breakup is significant, not only for hydraulic engineers but also for hydrologists modeling snowmelt processes at the watershed scale. In the modeling process, river discharge is the output to the system; thus, knowing river discharge during breakup is fundamental. While measurements can be taken using propellers, an Acoustic Doppler Velocimeter (ADV), and an Acoustic Doppler Current Profiler (ADCP) mounted on boats or tethered to a field crew member, the methodologies developed for using this equipment are based on normal (i.e., ice- and debris-free) river conditions. The presence of ice in the channel (shore, bottom, and floating) adds another layer of complexity to the task of gauging a stream.

Figure 1a-d shows specific fieldwork challenges during breakup: river access difficulties due to riverbanks covered by snow and/or ice, precluding the possibility of launching a boat in the water, and extensive floating ice, a safety hazard for occupants of a boat. In the case of a braided river, such as the Sagavanirktok River in Alaska, multiple channels present another challenge when gauging the entire river.

A danger of boat travel on a river during breakup in arctic regions is loss of motor power, which in the case of a jetboat can occur when gravel or particles of ice clog the intake. A boat without power 
moves in the direction of the river currents, and obstacles put all occupants at risk. Additionally, the Sagavanirktok River is in a remote region, where a call for assistance does not mean immediate help.

During breakup in 2015, unprecedented flooding of the Sagavanirktok River occurred. The only transportation access route to the oil fields — the Dalton Highway-was breached in several locations and severely damaged by the flooding [2]. Each spring since 2015, a University of Alaska Fairbanks (UAF) research team has performed discharge measurements during breakup. The challenges encountered by the research team at this time of year and the approach it uses in performing discharge measurements (i.e., helicopter support) are described here.
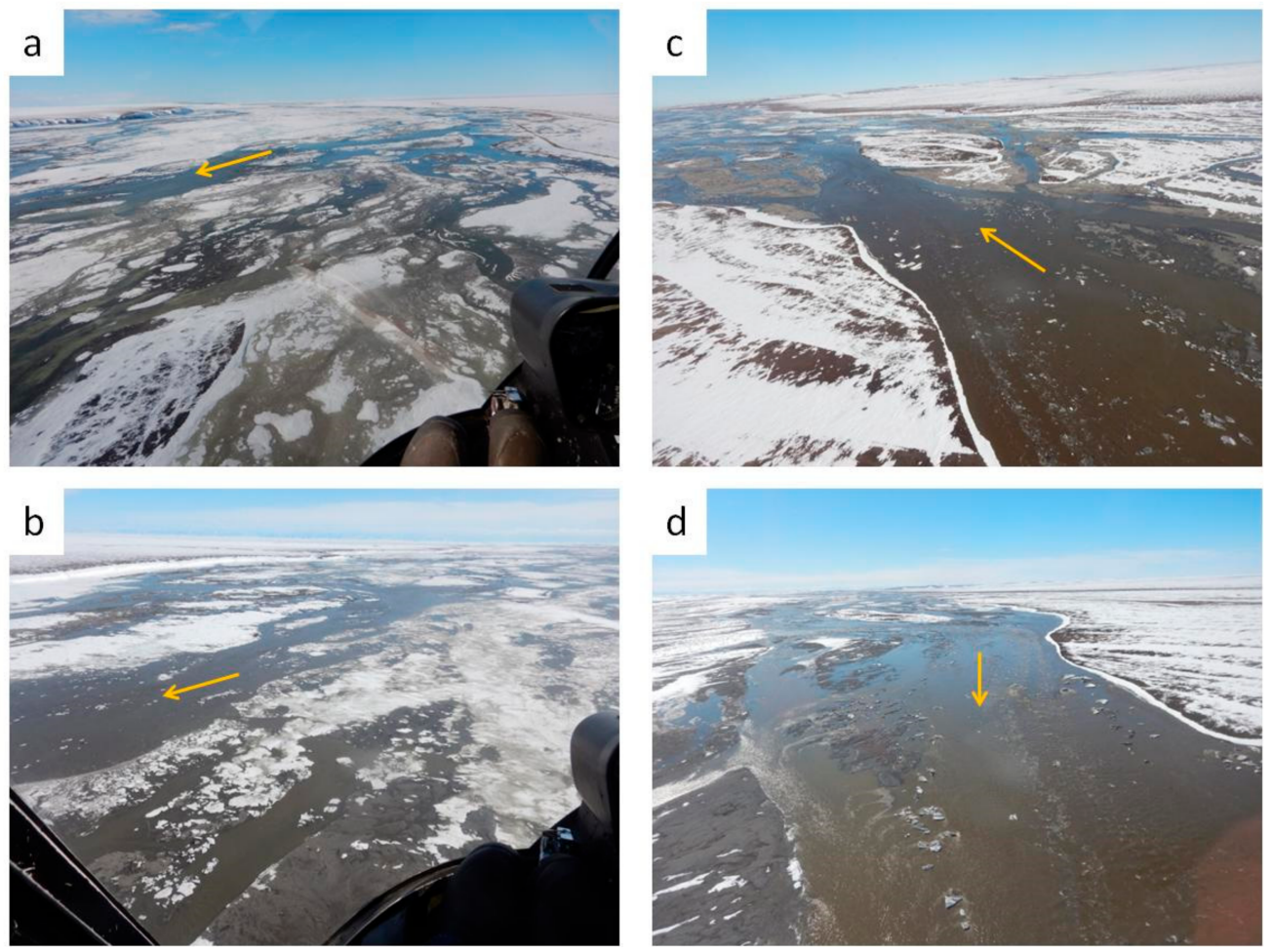

Figure 1. Sequential aerial views of the Sagavanirktok River during breakup 2017: (a) multiple channels flowing during the early stages of breakup; (b) flow complexity increases as breakup progresses; (c) extensive ice floating along the well-defined channels; and (d) banks near the road system still covered by snow and ice, making river access impossible. Arrows indicate flow direction.

\section{Equipment Setup and Field Crew}

The equipment we use during discharge measurements consists of an ADCP RiverPro (Teledyne RD Instruments, Poway, CA, USA) mounted on a high-speed trimaran (Teledyne Oceanscience, Poway, CA, USA), and a differential GPS (Hemisphere S321), which is connected to the ADCP. The trimaran is tethered to a Robinson R44 Raven helicopter. Communication between the equipment in the water and the computer that is recording the measurements, using WinRiver II (a software developed by Teledyne RD Instruments), on the helicopter is established by a wireless connection. A 15 m nylon line links the trimaran and the helicopter, and a $5 \mathrm{~kg}$ weight is placed near the end of the line, close to the trimaran (Figure 2). The weight is used to improve the trimaran's displacement along the river cross section. A set of orange panels deployed near the river transects improves the pilot's orientation over the moving water.

The helicopter crew consists of three people: the pilot, a spotter, and a computer operator. On the ground, another person provides logistical support to the crew. The use of the helicopter helps the research team find acceptable locations for measuring discharge on any given day during breakup. The helicopter makes it possible to measure multiple channels in a river cross section. 

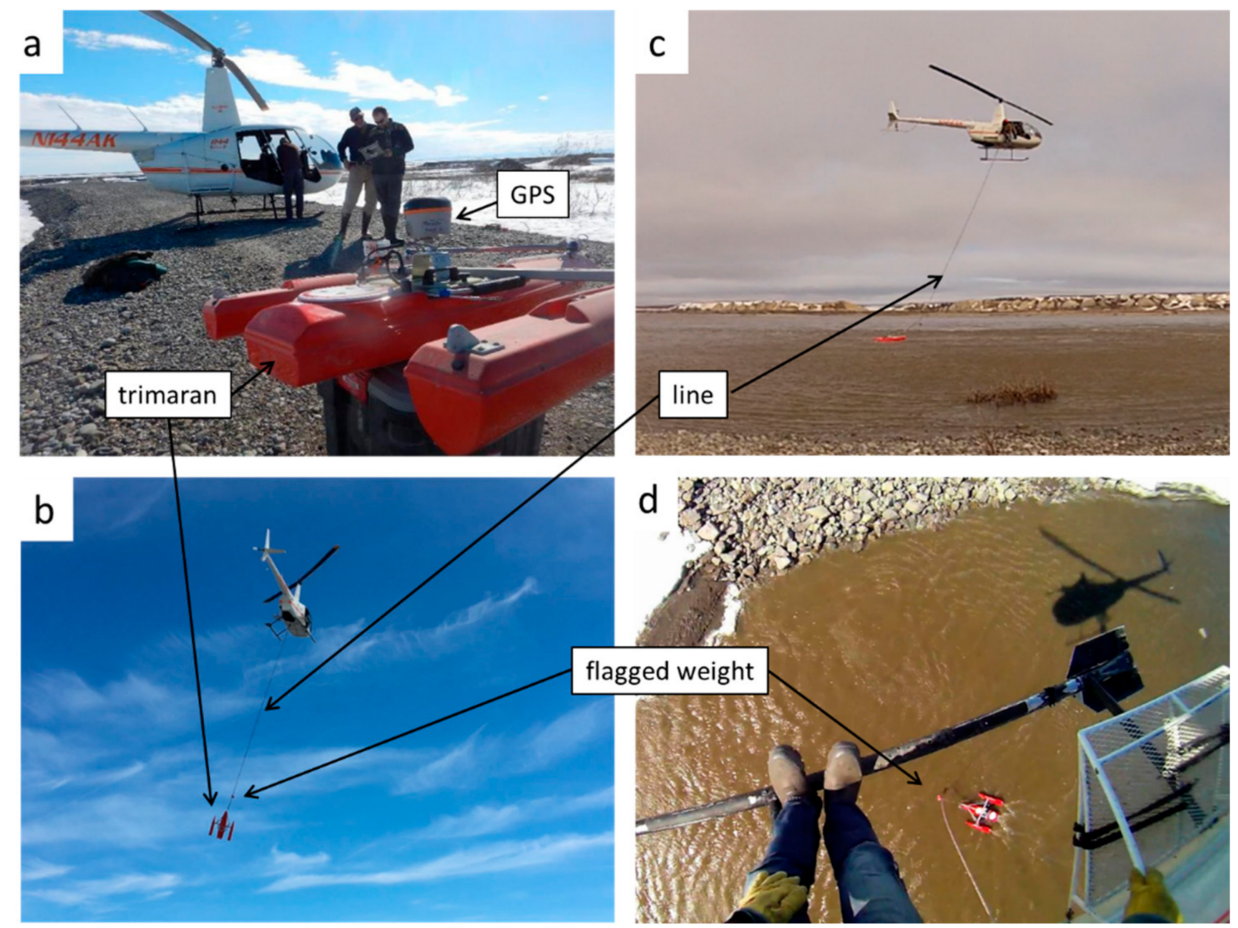

Figure 2. Field configuration setup and gauging tasks: (a) front: GPS mounted on trimaran, back: personnel doing pre-measurement tasks; (b) helicopter slinging trimaran; (c) trimaran positioned in the channel; and (d) view of trimaran, sling line, and weight in front of trimaran during a measurement.

\section{Methodology}

Before discharge measurements are taken, the helicopter pilot and the crew make reconnaissance flights to locate areas where the flow is relatively confined. After these locations are identified, orange panels are deployed at the inner bank to improve the pilot's orientation.

We calibrate the ADCP compass prior to measuring, with the equipment in place on the trimaran (Figure 2a) and the helicopter on the ground. The helicopter lifts the trimaran and positions it near one of the channel banks to start the river transects. We make a minimum of two transects in each direction (left to right and right to left) to calculate the average discharge using WinRiver II, and assign a rating for each measurement following standard practices [1,3,4]. Total discharge is obtained by adding the discharges of all individual channels.

Onboard the helicopter, the main function of the spotter is to observe and assist the pilot in adjusting the position of the aircraft relative to the trimaran. This arrangement frees the pilot from watching the sling load and allows the pilot to concentrate on fixed landmarks, mitigating the visually disorientating effects of moving water below. The spotter helps adjust the position of the trimaran by guiding the pilot in movements of the helicopter. Possible adjustments include altitude correction, transect positioning (beginning and end), obstacle avoidance (i.e., ice), transect speed moderation, and maneuver variations when changing water velocities and back-eddies are encountered.

The objective of the pilot is to guide the helicopter in pulling the trimaran smoothly from bank to bank with uninterrupted water contact. The most common aircraft adjustment is to go up or go down. When the trimaran is on the water and oriented in the current, the sling line does not hang vertically but trails downstream. The amount of trailing can vary and is somewhat determined by conditions-water velocity, wind, etc. The trailing of the line creates slack for the helicopter and trimaran positions to change to a degree before correction is needed. As the transect progresses, the helicopter imperceptibly gains or loses altitude, especially in windy weather. These vertical changes are readily apparent to the spotter, watching the trimaran and sling line. If the helicopter gains altitude, the line trailing decreases, 
causing the trimaran to come more directly underneath the aircraft. If this occurs, the trimaran could be pulled out of the water, disrupting transect data collection. When the line is pulled high near its tolerance, the spotter calls to the pilot, "down" or "down a little" or "down, down, down," until the desired adjustment is reached; then the spotter calls "good!" Conversely, if the helicopter loses altitude, the line and trimaran will trail farther downstream. The spotter, deeming adjustment necessary, calls "up," etc., until a satisfactory position is reached. It has been our practice to attach a weight $(5 \mathrm{~kg}$ lead diving weight) approximately $1 \mathrm{~m}$ up the sling line from the rigid trimaran attachment yoke. This weight is wrapped with highly visible surveyor flagging (Figure 2d). The weight causes a sharp angle in the line at its location, allowing the short length between the weight and trimaran to be parallel with the trimaran's travel direction. This method results in more "give" in the system at the angle point. The weight with surveyor flagging also provides the spotter an excellent reference point for vertical correction. On days when the sun casts a strong shadow, the height of the lead weight above the water surface is easily determined by the difference between object and shadow. Generally, well-adjusted altitude keeps the weight from dipping in the water, but allows enough slack (trailing) in the line to avoid pulling the trimaran out of the water.

While altitude control is the largest portion of the spotter's task, the need for more complex aircraft maneuvers involving horizontal positioning can arise. The commands used in this task are "left," "right," "ahead (forward)," "back (reverse)," "hold position," etc. The best terms to use are simple and clearly understood. The spotter needs to be mindful of the helicopter's facing and adjust directional terms accordingly; the pilot may choose facing based on wind direction and not the river or the transect. As there is some time lag between movement of the helicopter and the corresponding movement of the trimaran, it is best to make horizontal adjustments incrementally, allowing the trimaran position plenty of time to stabilize so that overcorrection is avoided. Ultimately, precise positioning is a combination of vertical and horizontal control, with constant feedback to the pilot from the spotter.

At the beginning and end of transect positioning, the spotter assists the pilot in easing the helicopter and trimaran as close to the bank as practical. The spotter checks with the ADCP instrument operator to ensure enough depth. When depth and distance are good, the spotter calls "hold position" and allows enough time to ensure that the trimaran position is stable. The spotter estimates the distance from the bank (the trimaran is approximately $1 \mathrm{~m}$ wide and is used as an indicator) and informs the instrument operator.

To begin a transect the operator starts recording and calls "go!" to the pilot and the pilot pulls the trimaran away from the bank. At the end of the transect, the operator stops recording and advises the crew. Vertical adjustment is continuous with horizontal adjustment. Positioning for a "loop" moving-bed test is similar except that an obvious and recognizable object or formation on the bank is chosen as the beginning and end, and ideally, that beginning position is reached at the conclusion of the loop. Occasionally in high-velocity water at the beginning of a transect, the trimaran "slingshots" away from the bank as it normalizes its position with the aircraft. The spotter, aware of this possibility, calls to the pilot to "hold" or "move out," which the pilot does incrementally, allowing time for the trimaran to normalize. Other times, the pilot may have difficulty judging transect speed (especially on wide channels and in wind), and the spotter helps moderate this condition. For avoiding floating ice and debris, the pilot, who has a larger view of the surroundings, usually informs the spotter of an oncoming object. Upon sighting the object, the spotter judges the best maneuver to avoid it. Areas of differing water velocities, back-eddies along banks and downstream of gravel bars, and wind also necessitate various adjustments.

The spotter needs to have a view directly below the helicopter, often behind it, and occasionally to the opposite underside of it. The aircraft doors are removed to allow unrestricted views in these directions. The spotter can remain seated with a fastened seatbelt and lean out, generally seeing in all necessary directions. The drawbacks of this arrangement are discomfort and spine fatigue from side-leaning and twisting for many minutes while measurements are in progress, since the need for 
surveillance and feedback is constant when the trimaran is on the water. The spotter may prefer to stand, attached by a harness, outside the helicopter on a skid. This position affords the spotter more observation flexibility and alleviates the long durations of sitting-side-leaning and twisting. While standing securely on the skid, the spotter can view the trimaran in a more comfortable posture, although some amount of forward leaning (hands braced on knees, and observing between the legs) is required when the trimaran is under the far side of the helicopter.

The main task for the computer operator is to run the software used to record the river measurements, similar to the tasks performed during discharge measurements using a boat.

Without a doubt, the pilot is the most important field crew member when using this approach to river discharge measurements. The following are the pilot's main considerations when flying a helicopter during measurements on the Sagavanirktok River.

Distinct outside references are necessary for accurate and consistent transects. Reference examples include the mouth of a tributary, a dike, a large rock pile, or an orange panel. These landmarks must be easily visible and stand out from the surrounding area. The foreground will be the fast-moving water of the river. The background will be the stationary banks and landmarks. However, the background will appear to be moving or "flowing" with the river in the foreground, creating an optical illusion-usually in peripheral vision. Vertigo, disorientation, and lack of vertical reference are a serious concern for the pilot. Depth perception over moving water is poor at best. Attempting to insert/extract or watch the trimaran without assistance from a spotter will cause disorientation and vertigo. Watching the trimaran will also cause the pilot to match the water flow with the aircraft. The pilot must use the spotter and maintain outside reference to stationary points. Vertigo and disorientation must be avoided at all costs-either can cause loss of aircraft control.

The maximum wind speed for helicopter operations with the trimaran is 20-25 aeronautical knots in clean air conditions. It will be lower if turbulence is present. The aircraft must be facing either upriver or downriver into the wind. For a crosswind the aircraft should be facing upriver. Crosswinds will "push" the aircraft in one direction and "resist" going the other. Either way, cross-river speed will be much more difficult to control. Traversing against the wind will cause the aircraft to pull the trimaran in a more incremental fashion with stops and starts. Traversing with the wind will cause the aircraft to overfly and force the trimaran to catch up with the aircraft. Maintaining an even speed is difficult. Crosswinds can also cause the trimaran to angle against the current, which may result in "cavitation" and inaccurate ADCP readings.

Once the trimaran is in the water, control inputs by the pilot must be slight. There is a delay from aircraft movement to trimaran movement. Too much input will cause the trimaran to move too quickly and produce low-quality transects or interruptions in data collection.

\section{Results and Conclusions}

During the measurements, the spotter was in constant communication with the pilot to ensure a smooth and continuous transect, consequently avoiding possible problems, such as lifting the ADCP out of the water. An example of the field conditions and the corresponding cross-sectional velocity profiles generated by WinRiver II are shown in Figure 3. After four transects were measured, the average discharge, the standard deviation, and the corresponding ratio between the standard deviation and the average discharge were calculated by WinRiver II (examples of summary tables generated by the software are included the Supplementary Material). This ratio is utilized to establish the quality of the measurement.

In the case of the Sagavanirktok River, the quality of the discharge measurements we have taken are in the good-to-fair range according to the scale used by the USGS [1,3]. Using a trimaran tethered to a helicopter, we are able to perform multiple discharge measurements. None would be possible using a conventional boat for this type of fieldwork without unacceptably high risk. These measurements are critical, both for hydraulic engineers studying river conditions during breakup and for hydrologists modeling snowmelt processes at the watershed scale. 
The use of a helicopter allows the selection of sites that capture the entire river flow, which in a braided river usually involves several channels. While the authors acknowledge the risk of flying in a helicopter, we consider that risk lower than the risk of attempting discharge measurements during breakup using a boat with the field crew onboard.

Finally, as existing drone technology continues to evolve, measurements using a drone-tethered ADCP may be possible-further reducing risk to personnel.
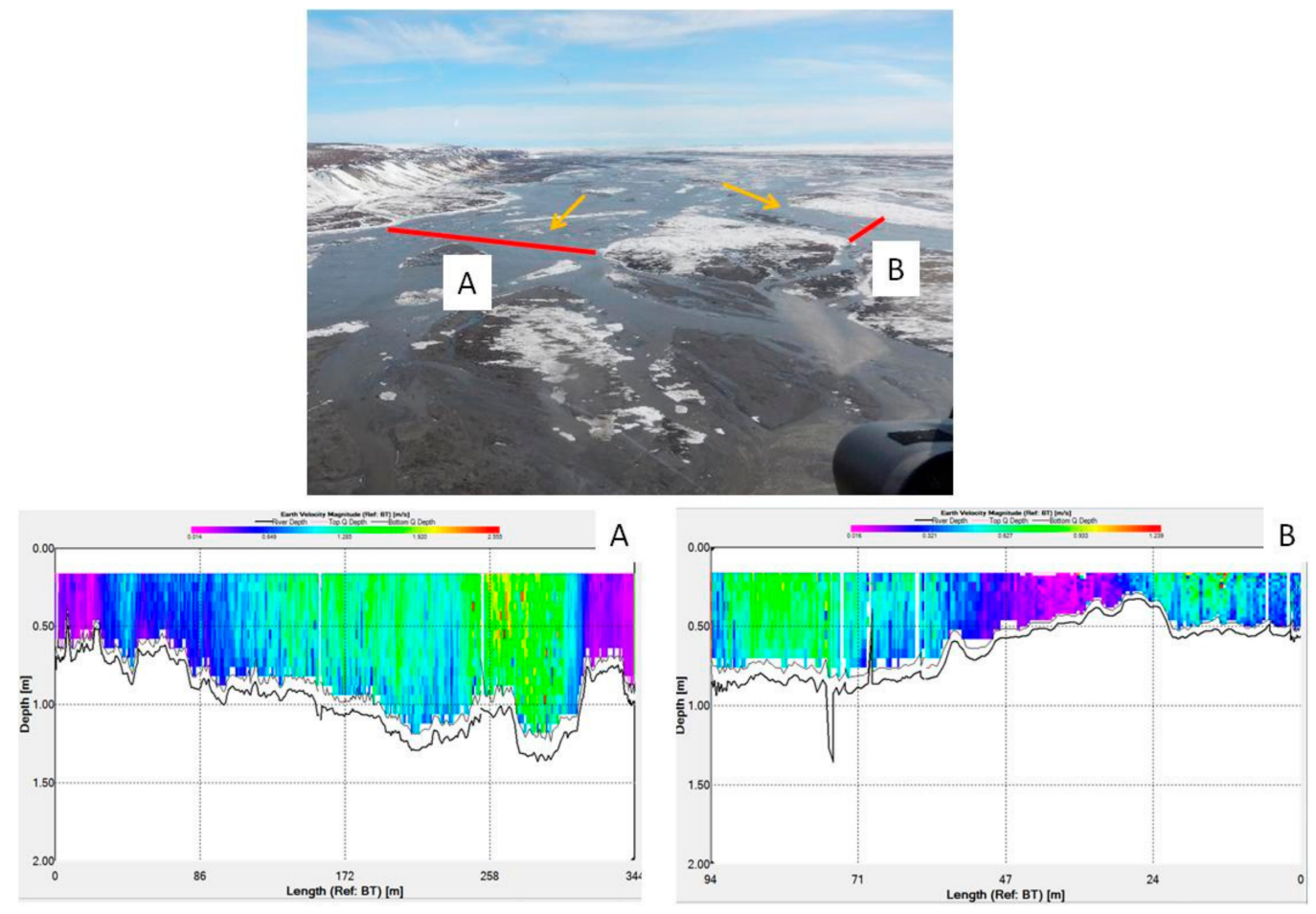

Figure 3. (Top) Field conditions and location of transects (red lines), where arrows indicate flow direction; and (bottom) cross-sectional velocity profiles generated by WinRiver II, where violet and red in the profiles indicate low and high velocity, respectively.

Supplementary Materials: The following is available online at http:/ /www.mdpi.com/2073-4441/10/6/697/s1. Examples of discharge measurement summaries on the Sagavanirktok River, Alaska, USA.

Author Contributions: All authors contributed to the manuscript: Spotter section (J.K.); pilot's thoughts (M.T.); equipment setup and figures (J.B.); and other sections (H.T.).

Funding: This work is part of the Sagavanirktok hydro-sedimentological study, which is funded by the Alaska Department of Transportation and Public Facilities, under grant \#ADN2572616 to the University of Alaska Fairbanks.

Conflicts of Interest: The authors declare no conflict of interest.

\section{References}

1. Mueller, D.S.; Wagner, C.R.; Rehmel, M.S.; Oberg, K.A.; Rainville, F. Measuring Discharge with Acoustic Doppler Current Profilers from a Moving Boat; (Ver. 2.0, Dec.): U.S. Geological Survey Techniques and Methods, Book 3; U.S. Geological Survey: Reston, VA, USA, 2013; Chapter A22; p. 95.

2. Toniolo, H.; Stutzke, J.; Lai, A.; Youcha, E.; Tschetter, T.; Vas, D.; Keech, J.; Irving, K. Antecedent conditions and damage caused by 2015 spring flooding on the Sagavanirktok River, Alaska. J. Cold Reg. Eng. 2017, 31, 19. [CrossRef] 
3. Mueller, D.S. Review and Rating of Moving-Boat ADCP Q Measurements. Hydroacoustics Webinar. September 2012. Available online: https:/ / hydroacoustics.usgs.gov/training/webinars.shtml (accessed on 10 July 2017).

4. Wagner, C.R.; Mueller, D.S. Comparison of bottom-track to global positioning system referenced discharges measured using an acoustic Doppler current profiler. J. Hydrol. 2011, 401, 250-258. [CrossRef] 